\title{
Fuzzy Fault Detection for Permanent Magnet Synchronous Motor
}

\author{
Alexander Romanov ${ }^{1, *}$ \\ ${ }^{1}$ Kalashnikov Izhevsk State Technical University, 7, Studencheskaya street, Izhevsk, 426069, Russia
}

\begin{abstract}
In the transition to automated and automatic manufacturing an urgent problem is to increase the reliability of mobile robots (MR) and their drives, creation of devices to monitor the technical characteristics of MR, diagnose and predict the remaining resource. Inspite of the high relevance of the diagnosing MR drives problem, there are no generally accepted methodology for diagnosing MR drives, criteria for selecting methods, parameters and volumes of diagnostics at present. An unsolved problem, related to the diagnosis of MR drives and the prediction of their residual life remains, is the development of methods that allow to carry out of automatic complex multiparametric diagnostics and prediction of the residual life using artificial intelligence methods. Effective fault detection and diagnosis can improve the reliability of the MR drive and avoid costly maintenance. In this paper a fault detection scheme for synchronous motors with permanent magnets based on a fuzzy system is proposed. The sequence current components (positive and negative sequence currents) are used as fault indicators and are set as input to the fuzzy fault detector. The expediency of the proposed scheme for determining of various types of faults for a synchronous motor with permanent magnets under various operating conditions is simulated using the SimInTech software.
\end{abstract}

\section{Introduction}

Three-phase drives based on high-power synchronous motors are widely used for mobile robots with high carrying capacity. The advantage of synchronous motors with permanent magnets (PMSM) is the absence of field windings on the rotor.

A number of approaches for online detection of electrical drive defects have been proposed in recent years [1], [2]. The model-based diagnostic concept is the most widely used approach due to the need for uninterrupted operation of mobile robot drives and increasing requirements for their reliability [3].

PMSM modeling is the first step in the development of diagnostic systems [4], [5]. Models show a complex relationship between parameters, accurate identification of a fault is very difficult. The accuracy of the drive model is limited due to its idealization. Environmental factors such as motor temperature and operational factors: speed and current may affect the fault signature [6]. Fault detection based on spectral analysis of vibration is

\footnotetext{
${ }^{*}$ Corresponding author: ms_istu@mail.ru
} 
considered in [7]. The disadvantages of this method are necessary to use the expensive high-precision vibration sensors.

The components of voltage and current imbalances are used to detect an inter-turn fault and are obtained from linear voltages and currents that are set as input data for a fuzzy fault detector [8]. A fault detection scheme for the PMSM drive, taking into account electrical defects such as stator resistance and inductance, is described in [9].

\section{PMSM fuzzy logic fault detection and identification system}

\subsection{PMSM defects classification}

PMSM defects such as follows: rotor defect, overload, defects in the mechanical and electrical parts of the motor, single-phase short-circuit to the housing, two-phase shortcircuit to the housing, and combined defect.

\section{Rotor defect (demagnetization)}

For PMSM, the main defect of the rotor is a defect in the magnets or their degradation, which is the result of a pulsating load or a manufacturing defect. Demagnetization of the rotor causes vibrations, vibrations, abnormal noises, etc.

\section{Overload (overheating)}

PMSM overload as well as overcurrent leads to its overheating. The maximum operating temperature of the motor usually does not exceed $90{ }^{\circ} \mathrm{C}$. High temperatures significantly reduce the service life of the engine, and prolonged exposure can cause it to break down.

\section{Mechanical part defects}

This type of defect is associated with a sudden change in the moment of inertia and coefficient of viscous friction, which can be caused by bearing defects, lack of lubrication, overload and eccentricity of the air gap. Defects in the mechanical part are characterized by excessive vibrations, which lead to incorrect operation of the motor, and in the future can lead to its breakdown.

\section{Electrical part defects}

Defects in the electrical part mainly occur due to abnormal changes in the resistance and inductance of the stator winding, which leads to their overheating.

\section{Single-phase enclosure fault}

This situation occurs when any of the phases is closed to the motor housing. In this case, the short-circuit current increases, the interfacial voltage at the fault point tends to zero, and the phase voltages make up half of the motor supply voltage. Due to the voltage drop, the motor speed and electromagnetic torque are significantly reduced.

\section{Two-phase enclosure fault}

Occurs when any two phases of the motor are closed to the housing. As in the case of a single-phase fault, the short-circuit current increases strongly, and the phase-to-phase voltage at the fault point tends to zero.

\section{Combined defect (overload and rotor defect)}

Overloading can physically affect on the rotor shaft, causing it to break or crack, which in turn will cause a decrease in magnetic flux, that will reduce the efficiency of the motor.

\subsection{Fuzzy fault detection system}

A block diagram of the proposed system for detecting and identifying PMSM faults based on fuzzy logic is shown in Figure 1. Fault identification is based on an assessment of the 
linear current imbalance [8]. An imbalance of the stator winding creates positive and negative current imbalances in the motor, which are used as fault indicators.

The positive Ia 1 and negative Ia 2 current imbalances are calculated from the linear currents of phases a, b, c as follows:

$$
\begin{aligned}
& I a I=1 / 3 \cdot\left(I a+\alpha I b+\alpha^{2} I c\right) \\
& I a 2=1 / 3 \cdot\left(I a+\alpha^{2} I b+\alpha I c\right)
\end{aligned}
$$

where $\alpha=-0.5+\mathrm{j} 0.866$ and $\alpha^{2}=-0.5-\mathrm{j} 0.866$.

The components of imbalances are affected in a certain way by each of the defects. Then fault is identified using a fuzzy output system. Possible faults are modeled and detected using fuzzy logic in the SimInTech simulation environment.

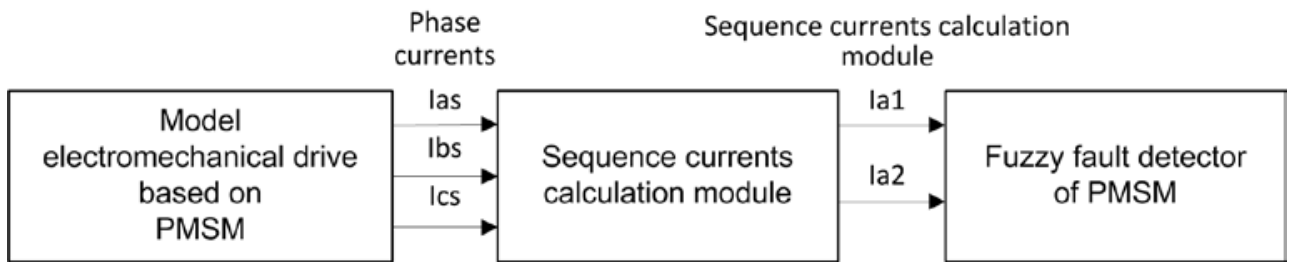

Fig. 1. Block diagram of fuzzy fault detection system

The model-based fuzzy fault detection system consists of 3 main components:

1.PMSM-based electromechanical drive model;

2. Current imbalance calculation module (calculates positive Ia1 and negative Ia2 current imbalances);

3. A fuzzy fault detector module (identifies an motor defect).

The system is used to generate positive and negative current imbalances calculated from linear currents in the operating and faulty motor states. The calculated unbalances are used as input parameters for the fuzzy system.

\subsection{PMSM fault modeling}

The model of investigated electromechanical drive of mobile robot with fuzzy detection and fault identification system in SimInTech software is shown in Figure 2.

The PMSM model is Balt Systems KM-08-02.0-030 (specification in Table 1). The moment of inertia of the external mechanical load $\mathrm{J}=390 \mathrm{~kg} \times \mathrm{cm}^{2}$.

Table 1. PMSM specification

\begin{tabular}{|l|c|}
\hline \multicolumn{1}{|c|}{ Parameter } & Value \\
\hline Stator phase inductance $(\mathrm{Ls})$ & $0.0053 \mathrm{Gn}$ \\
\hline Stator phase resistance $(\mathrm{Rs})$ & $1 \mathrm{Om}$ \\
\hline Rotor flow coupling $(\psi)$ & $0,4 \mathrm{~Wb}$ \\
\hline Rotor moment of inertia $(\mathrm{J})$ & $2 \mathrm{~kg} \times \mathrm{cm}^{2}$ \\
\hline Coefficient of viscous friction $(\mathrm{Bm})$ & $0.5 \mathrm{~N} * \mathrm{~m}^{*} \mathrm{~s}$ \\
\hline
\end{tabular}




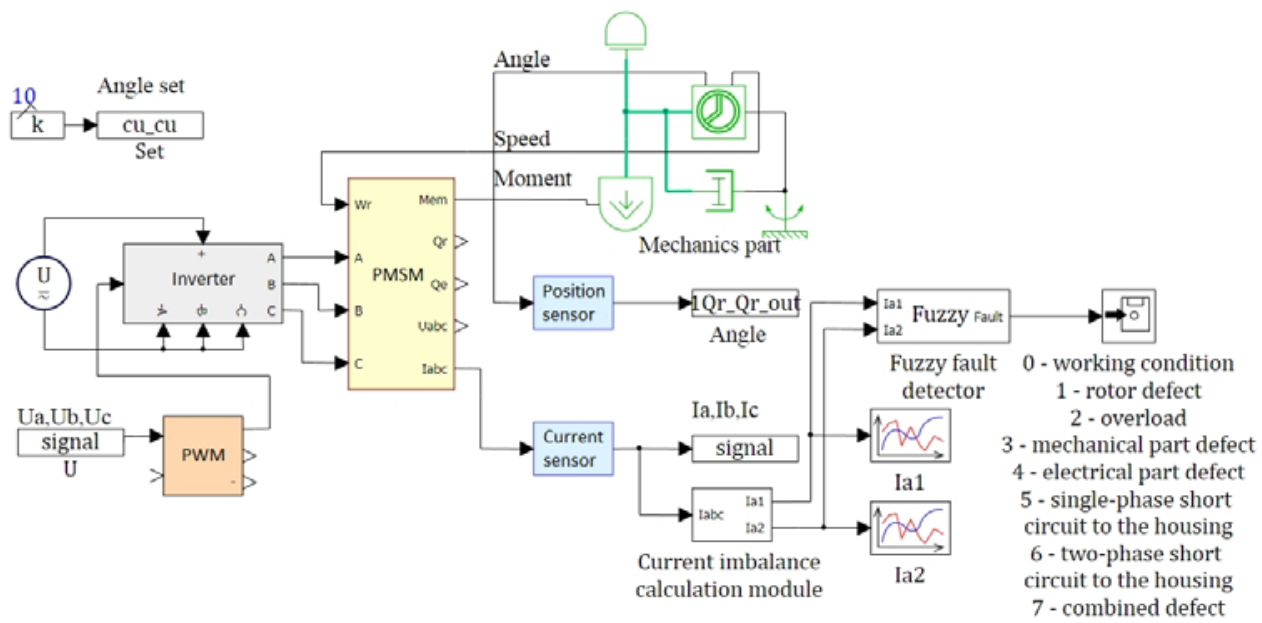

Fig. 2. Model of electromechanical drive based on PMSM

The normal state of PMSM are presented on figures 2 (a-c).

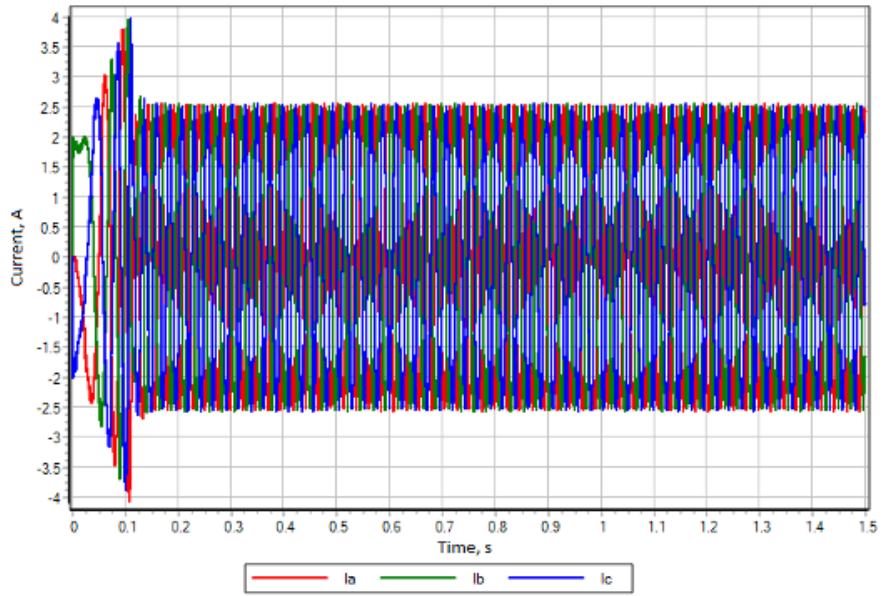

a)

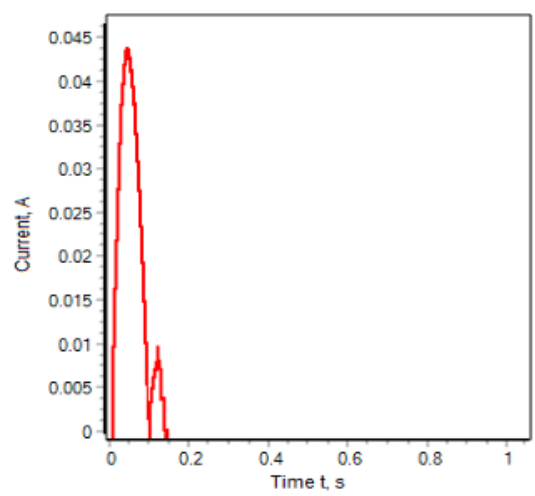

b)

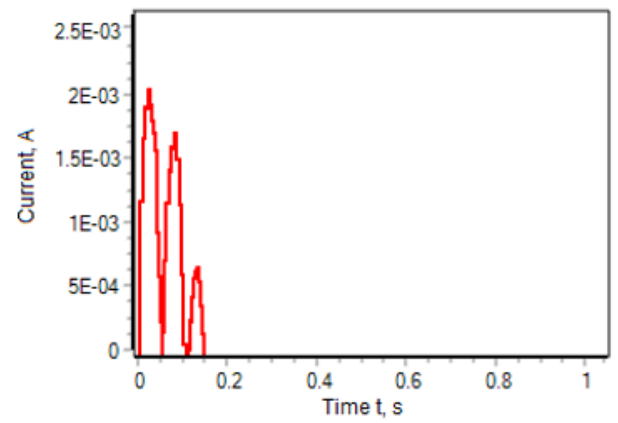

c)

Fig 3. Diagram of motor (serviceable state): a) phase currents; b) positive current imbalance; c) negative current imbalance; 
The PMSM fault simulation was carried out as follows ${ }^{\wedge}$

\section{Overload (overheating)}

Overload is modeled by changing the shaft load $\left(T_{L}\right)$ from $100 \%$ to $200 \%$ of the rated load.

\section{Rotor demagnetization}

Rotor failure is modeled by a reduction in flow $(\psi)$ to $25 \%$ of the nominal value.

Mechanical part defect

A mechanical failure is modeled by a change in $\mathrm{J}$ and $\mathrm{Bm}$ from $100 \%$ to $200 \%$ of the nominal values.

\section{Combined defect (overload and rotor defect)}

The combined defect is modeled by simultaneously reducing the flow $(\psi)$ to $25 \%$ of the nominal value and changing the shaft load $\left(\mathrm{T}_{\mathrm{L}}\right)$ from $100 \%$ to $200 \%$ of the nominal.

\section{PMSM fuzzy fault detector}

To ensure the accuracy of the PMSM fault identification system is recommended to assign an odd number of partitioning terms to each variable. The range of changes in the linguistic variables "positive current imbalance" Ial is divided into eleven sets, "negative current imbalance" Ia2 - into thirteen sets, and the linguistic variable "malfunction" - into eight on a base of experimental data obtained as a result of modeling,

It is necessary to define the ranges of changes in input and output variables when defining linguistic variables, After that, the range of changes in each variable is divided into sets, and it is necessary to choose the type of membership function.

In most of the works devoted to the development of fuzzy diagnostic systems, triangular functions are used as membership functions, due to the high speed of operation and good accuracy.

Thus, to describe the input variable Ia1 applies fuzzy variable with eleven triangular

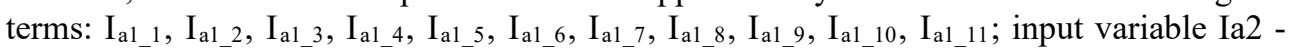
fuzzy variable with thirteen triangular terms: $\mathrm{I}_{\mathrm{a} 2{ }_{-} 1}, \mathrm{I}_{\mathrm{a} 2 \_}, \mathrm{I}_{\mathrm{a} 3 \_3}, \mathrm{I}_{\mathrm{a} 3 \_4}, \mathrm{I}_{\mathrm{a} 3 \_5}, \mathrm{I}_{\mathrm{a} 3-6}, \mathrm{I}_{\mathrm{a} 3-7}, \mathrm{I}_{\mathrm{a} 3 \_8}$, $\mathrm{I}_{\mathrm{a} 3 \_9}, \mathrm{I}_{\mathrm{a} 3 \_10}, \mathrm{I}_{\mathrm{a} 3 \_11}, \mathrm{I}_{\mathrm{a} 3 \_12}, \mathrm{I}_{\mathrm{a} 3 \_13 \text {. }}$

For linguistic descriptions of the output variable is a fuzzy variable with eight triangular terms: serviceable (S), overload (OL), rotor defect (RD), mechanical part defect (MD), electrical parts defect (ED), a single-phase circuit to the housing (SC), two-phase circuit to the housing (DC), a combined defect (defect of the rotor and overload) (CD).

It is necessary to reduce the signals to the range $[-1,1]$ in digital systems by using the input signal normalization and output signal denormalization procedures. The normalization coefficients $\mathrm{K}_{\mathrm{I} 11}, \mathrm{~K}_{\mathrm{I} a 22}$ for the input variables are determined based on the maximum possible values of positive and negative current imbalances obtained during modeling for the corresponding type of PMSM. The denormalization coefficient $\mathrm{K}_{\mathrm{FAULT}}$ for the output variable is determined in such a way as to provide an integer value of the corresponding fault in order to simplify the visual perception of diagnostic information.

Positive current imbalance:

$$
K_{\text {Ial }}=1 / \max |\operatorname{Ia1}|
$$

Negative current imbalance:

$$
K_{\text {Ia } 2}=1 / \max |\operatorname{Ia} 2|
$$

Output variable:

$$
K_{\text {FAULT }}=7
$$


The following values were used to assign the boundaries of the ranges of linguistic variables: positive Ia1 and negative Ia2 current imbalances - from 0 to maximum (current with a two-phase short-circuit to the housing).

The values of the normalizing coefficients are shown in Table 2.

Table 2. Normalization coefficients

\begin{tabular}{|c|c|}
\hline Normalization factor & Value \\
\hline $\mathrm{K}_{\mathrm{I} 2}$ & 0.0001639 \\
\hline $\mathrm{K}_{\mathrm{Ia} 2}$ & 0.0001639 \\
\hline $\mathrm{K}_{\mathrm{FAULT}}$ & 7 \\
\hline
\end{tabular}

The ranges of changes in linguistic variables are shown in Tables 3-5.

Table 3. Ranges of changes in input linguistic variables for Ia1

\begin{tabular}{|c|c|c|}
\hline & Positive current imbalance Ia1 & $\begin{array}{c}\text { Corresponding } \\
\text { PMSM fault }\end{array}$ \\
\hline $\mathrm{I}_{\mathrm{a} L_{-} 1}$ & $0 ; 0.00000328$ & $\mathrm{~S}$ \\
\hline $\mathrm{I}_{\mathrm{a} 1 \_2}$ & $0 ; 0.000006884$ & $\mathrm{RD}, \mathrm{S}$ \\
\hline $\mathrm{I}_{\mathrm{aa1} \_3}$ & $0.000003442 ; 0.000007458$ & $\mathrm{OL}, \mathrm{SC}$ \\
\hline $\mathrm{I}_{\mathrm{a} 1 \_4}$ & $0.000005737 ; 0.000006719$ & $\mathrm{RD}$ \\
\hline $\mathrm{I}_{\mathrm{a} 1 \_5}$ & $0.000006228 ; 0.000008196$ & $\mathrm{~S}$ \\
\hline $\mathrm{I}_{\mathrm{a} 1 \_6}$ & $0.000006228 ; 0.000008428$ & MD \\
\hline $\mathrm{I}_{\mathrm{a} 1 \_7}$ & $0.000007328 ; 0.00001095$ & $\mathrm{CD}, \mathrm{ED}, \mathrm{MD}$ \\
\hline $\mathrm{I}_{\mathrm{a} 1 \_8}$ & $0.00000914 ; 0.0001121$ & $\mathrm{SC}$ \\
\hline $\mathrm{I}_{\mathrm{a} 1 \_9}$ & $0.00006064 ; 0.00007376$ & ED \\
\hline $\mathrm{I}_{\mathrm{a} 1 \_10}$ & $0.0000672 ; 0.000981$ & $\mathrm{OL}$ \\
\hline $\mathrm{I}_{\mathrm{a} \_11}$ & $0.000524 ; 1$ & $\mathrm{DC}$ \\
\hline
\end{tabular}

Table 4. Ranges of changes in input linguistic variables for Ia2

\begin{tabular}{|c|c|c|}
\hline & $\begin{array}{c}\text { Negative current } \\
\text { imbalance Ia2 }\end{array}$ & $\begin{array}{c}\text { Corresponding } \\
\text { PMSM fault }\end{array}$ \\
\hline $\mathrm{I}_{\mathrm{a} 2}{ }_{1}$ & $0 ; 0.00000009834$ & $\mathrm{~S}$ \\
\hline $\mathrm{I}_{\mathrm{a} 2} 22$ & $0 ; 0.0000005518$ & $\mathrm{~S}$ \\
\hline $\mathrm{I}_{\mathrm{a} 2} 3$ & $0.0000002759 ; 0.0000004125$ & $\mathrm{~S}$ \\
\hline $\mathrm{I}_{\mathrm{a} 24}$ & $0.0000003442 ; 0.000001065$ & MD \\
\hline $\mathrm{I}_{\mathrm{a} 2 \_5}$ & $0.0000007212 ; 0.0009113$ & OL \\
\hline $\mathrm{I}_{\mathrm{a} 2}-6$ & $0.000004917 ; 0.00001147$ & $\mathrm{SC}$ \\
\hline $\mathrm{I}_{\mathrm{a} 2}-7$ & $0.000008195 ; 0.000017005$ & $\mathrm{RD}$ \\
\hline $\mathrm{I}_{\mathrm{a} 2 \_} 8$ & $0.0000126 ; 0.00003002$ & RD, ED \\
\hline $\mathrm{I}_{\mathrm{a} 2}-9$ & $0.00002131 ; 0.00003441$ & $\mathrm{~S}$ \\
\hline $\mathrm{I}_{\mathrm{a} 2 \_10}$ & $0.00002786 ; 0.00009342$ & $\mathrm{SC}$ \\
\hline $\mathrm{I}_{\mathrm{a} 2 \_11}$ & $0.00006064 ; 0.0001786$ & $\mathrm{CD}, \mathrm{OL}$ \\
\hline $\mathrm{I}_{\mathrm{a} 2 \_12}$ & $0.0001196 ; 0.0005504$ & OL \\
\hline $\mathrm{I}_{\mathrm{a} 2 \_13}$ & $0.000335 ; 1$ & DC \\
\hline
\end{tabular}


Table 5. Ranges of changes in output linguistic variables

\begin{tabular}{|c|c|}
\hline Fault & Value \\
\hline Serviceable (working condition, no faults) & $0 ; 0,143$ \\
\hline Rotor defect & $0 ; 0.286$ \\
\hline Overload & $0.143 ; 0.429$ \\
\hline Mechanical part defect & $0.286 ; 0.572$ \\
\hline Electrical part defect & $0.429 ; 0.715$ \\
\hline Single-phase short circuit to the housing & $0.572 ; 0.858$ \\
\hline Two-phase short circuit to the housing & 0,$715 ; 1$ \\
\hline Combined defect & $0.858 ; 1$ \\
\hline
\end{tabular}

If a PMSM fault is detected, it requires an immediate shutdown of the mobile robot's drive, otherwise it may fail.

The degree of belonging of this variable is equal to 1 when a linguistic variable goes out of range,

The rules database for the fault detector block based on the ranges of splitting linguistic variables and the ranges corresponding to faults.

Rules are drawn up based on variations in the values of current imbalances for different types of faults using expert knowledge.

Rules are formed by the type IF ... AND ..., THEN ...

Here are some of them:

- if the positive current imbalance Ia1 is equal to Ia1_2, and the negative current imbalance Ia2 is equal to Ia2_7, then the robot drive is faulty (rotor defect).

Similarly, the rules can be formulated for other input values.

The final database of fault detector rules with fuzzy output, which includes 32 production rules, is shown in Table 6.

Table 6. Fault detector rule base

\begin{tabular}{|c|c|c|}
\hline Malfunction & $\begin{array}{c}\text { Positive current } \\
\text { imbalance Ia1 }\end{array}$ & $\begin{array}{c}\text { Negative current } \\
\text { imbalance Ia2 }\end{array}$ \\
\hline Serviceable (working condition) & Ia1_1, Ia1_2, Ia1_5 & Ia2_1, Ia2_2, Ia2_3, Ia2_9 \\
\hline Rotor defect & Ia1_2, Ia1_4 & Ia2_7, Ia2_8 \\
\hline Overload & Ia1_3, Ia1_10 & Ia2_5, Ia2_11, Ia2_12 \\
\hline Mechanical part defect & Ia1_6, Ia1_7 & Ia2_4 \\
\hline Electrical part defect & Ia1_7, Ia1_9 & Ia2_8 \\
\hline Single-phase enclosure fault & Ia1_3, Ia1_8 & Ia2_6, Ia2_10 \\
\hline Two-phase enclosure fault & Ia1_11 & Ia2_13 \\
\hline Combined defect & Ia1_7 & Ia2_11 \\
\hline
\end{tabular}

The formulated rule base describes all possible combinations of input linguistic variables and the corresponding value of the output variable. This approach eliminates the possibility of uncertainty in the solution of the fuzzy inference system.

Fuzzy output is performed by Mamdani type.

Detected faults causing the output linguistic variable "Fault" are classified as follows:

1. Fault $=0$ - input variables Ia1, Ia2 correspond to the good motor condition;

2. Fault $=1$ - input variables Ia1, Ia2 correspond to the rotor defect condition;

3. Fault $=2$ - input variables Ia1, Ia 2 correspond to the motor overload condition;

4. Fault $=3$ - input variables Ia1, Ia 2 correspond to the condition of motor mechanical defect;

5. Fault=4 - input variables Ia1, Ia2 correspond to the condition of motor electrical 
defect (change of Rs and Ls);

6. Fault $=5$ - input variables Ia1, Ia 2 correspond to the condition of a single-phase short circuit to the motor housing;

7. Fault $=6$ - input variables Ia1, Ia 2 correspond to the condition of a two-phase short circuit to the motor housing;

8. Fault $=7$ - input variables Ia1, Ia 2 correspond to the condition of a combined motor defect.

\section{Conclusion}

The main defects of synchronous motors with permanent magnets are considered: a defect of the rotor (magnet), defects in the mechanical and electrical parts of the motor, a singlephase short-circuit to the housing, a two-phase short-circuit to the housing, and a combined defect. Their influence on the diagnostic parameters of the engine is revealed.

A system for detecting and identifying faults in synchronous motors based on fuzzy logic has been developed by evaluating current imbalances. The simulation of motor failures and the evaluation of changes in its diagnostic parameters are carried out.

\section{References}

1. G.B. Kliman, W.T. Premerlati, R.A. Roegl, D.A Hoeweler, A new approach to on line fault detection in AC motors, IEEE Conference on Industry Applications, v.1, pp. 687693 (1996)

2. J. Sottiled, J.K. Kohler, An on-line method to detect incipient failure of turn insulation in random-wound motors, Proceedings of IEEE Transactions on Energy Conversion, v. 4(8) (1993)

3. J. Penman, H.G. Sedding, B.A. Lloid, W.T. Fink, Detection and location of inter-turn short circuits in the stator windings of operating motors, Proceedings of IEEE Transactions on Energy Conversion, v. 4(9), pp. 652-658 (1994)

4. H. Jiang, R. Aggarwal, G. Weller, S. Ball, L. Denning, A new approach to synchronous generator internal fault simulation using combined winding function theory and direct phase quantitie, Ninth International Conference on Electrical Machines and Drives, pp. 105-111 (1999)

5. G.M. Joksimovic, J. Penman, The detection of inter-turn short circuits in the stator windings of operating motor, IEEE Transactions on Industrial Electronics, v. 5(47), pp. 1078-1084 (2000)

6. Amol S. Kulkarni, Development of a technique for on-line detection of shorts in field windings of turbine-generator rotors: circuit design and testin, IEEE Transactions on Energy Conversion, v. 1(15), pp. 8-13 (2000)

7. W.S. Tommy, Tan Hong-Zhou. HOS-based nonparametric and parametric methodologies for machine fault detection, IEEE Transactions on Industrial Electronics, v. 5(47), pp. 1051-1059 (2000)

8. Dawei Xiang, Li Ran, Peter J. Tavner, Schunchang Yang, Control of doubly fed induction generator in a wind turbine during grid fault ride-through, IEEE Transaction on Energy conversion, v. 3(21), pp. 652-662 (2006)

9. Li Liu, David A. Cartes, On-line identification and robust fault diagnosis for nonlinear PMSM drives, Proceedings of the American Control Conference, v. 3, pp. 2023-2027 (2005) 